\title{
Analyzing nanotextured transparent conductive oxides for efficient light trapping in silicon thin film solar cells
}

Rahul Dewan, Jorj I. Owen, Darin Madzharov, Vladislav Jovanov, Jürgen Hüpkes, and Dietmar Knipp

Citation: Appl. Phys. Lett. 101, 103903 (2012);

View online: https://doi.org/10.1063/1.4750242

View Table of Contents: http://aip.scitation.org/toc/apl/101/10

Published by the American Institute of Physics

\section{Articles you may be interested in}

Light trapping in thin-film silicon solar cells with integrated diffraction grating Journal of Applied Physics 106, 074901 (2009); 10.1063/1.3232236

Optical enhancement and losses of pyramid textured thin-film silicon solar cells Journal of Applied Physics 110, 013101 (2011); 10.1063/1.3602092

PEDOT:PSS with embedded $\mathrm{TiO}_{2}$ nanoparticles as light trapping electrode for organic photovoltaics Applied Physics Letters 108, 253302 (2016); 10.1063/1.4954902

Detailed Balance Limit of Efficiency of $p$-n Junction Solar Cells Journal of Applied Physics 32, 510 (1961); 10.1063/1.1736034

Simultaneous enhancement of carrier mobility and concentration via tailoring of Al-chemical states in $\mathrm{Al}-\mathrm{ZnO}$ thin films

Applied Physics Letters 106, 241903 (2015); 10.1063/1.4922732

Effective light trapping in thin film silicon solar cells from textured Al doped $\mathrm{ZnO}$ substrates with broad surface feature distributions

Applied Physics Letters 100, 263508 (2012); 10.1063/1.4731775

\section{Scilight} Sharp, quick summaries illuminating the latest physics research

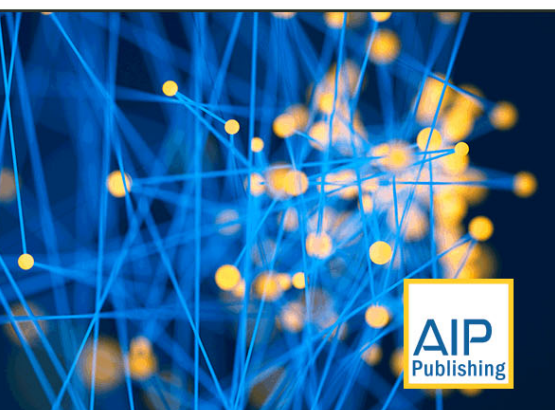




\title{
Analyzing nanotextured transparent conductive oxides for efficient light trapping in silicon thin film solar cells
}

\author{
Rahul Dewan, ${ }^{1}$ Jorj I. Owen, ${ }^{2}$ Darin Madzharov, ${ }^{1}$ Vladislav Jovanov, ${ }^{1}$ Jürgen Hüpkes, ${ }^{2}$ \\ and Dietmar Knipp ${ }^{1, a)}$ \\ ${ }^{1}$ Research Center for Functional Materials and Nanomolecular Science, Electronic Devices \\ and Nanophotonics Laboratory, Jacobs University Bremen, 28759 Bremen, Germany \\ ${ }^{2}$ Research Center Jülich, Institute of Energy Research-Photovoltaics, 52425 Jülich, Germany
}

(Received 30 March 2012; accepted 21 August 2012; published online 4 September 2012)

\begin{abstract}
Nanotextured contact layers are used in silicon thin film solar cells for increasing the short circuit current and conversion efficiency. We developed an approach to analyze random nanotextured surfaces by atomic force microscopy and image segmentation. It was used to investigate sputtered and wet chemically etched aluminum doped zinc oxide films with various morphologies. The information extracted from the surfaces was correlated with optical simulations of periodically textured thin film solar cells. The results from the surface analysis and optical simulations were also compared with the experimental results obtained for amorphous silicon solar cells prepared on the nanotextured substrates. (C) 2012 American Institute of Physics. [http://dx.doi.org/10.1063/1.4750242]
\end{abstract}

Light-trapping in thin film solar cells allows for both a reduction of the reflection losses and an increase in the optical path length of the incident light inside the solar cell. Different light trapping methods have been proposed for increasing the absorption of light in thin film solar cells. ${ }^{1-7}$ It has been demonstrated that introducing randomly textured interfaces is a very effective approach for increasing the absorption of light in thin film solar cells. ${ }^{4-6}$ Light is diffracted and scattered upon entering the solar cell, leading to an increase of the short circuit current and conversion efficiency. Randomly textured surfaces can be fabricated by wet etching of sputtered zinc oxide films, ${ }^{4}$ or during deposition by low pressure chemical vapor deposition (LPCVD) of zinc oxide or tin oxide. ${ }^{5,6}$ The surface of the sputtered and subsequently etched zinc oxide film is characterized by a random arrangement of craters, while the surface of the low pressure chemical vapor deposited film can be described by a random arrangement of pyramids. Fig. 1(a) shows a schematic cross section of a solar cell with textured contact layers. Fig. 1(b) shows a scanning electron microscopy (SEM) image of a textured zinc oxide film with craters, formed by sputtering and subsequent wet chemical etching.

Characterization and optimization of randomly textured surfaces is complex. Various approaches have been suggested to characterize and optimize the substrates, including optical measurements of the haze, which is given by the ratio of the diffuse and total (specular plus diffuse) transmitted light. Furthermore, measurements of the angular distribution function (ADF) have been carried out to gain insights into the diffraction and scattering behavior of nanotextured surfaces. ${ }^{8}$ These measurements, however, cannot be directly correlated with solar cell parameters like the quantum efficiency or the short circuit current. Alternative approaches have been presented by several authors using direct measurements of the nanotextured surfaces by atomic force microscopy (AFM). Dominé et al. ${ }^{9}$ and Bittkau et al. ${ }^{10}$ treated the textured surface as a phase

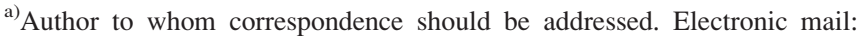
d.knipp@jacobs-university.de.
}

mask. By calculating the Fourier transform of the AFM images, the scattering properties can be determined. Franken et al. characterized the surface by calculating the power spectral density function, which is given by the Fourier transform of the autocorrelation function of the AFM images. ${ }^{11}$ Stiebig et al. suggested an approach to calculate the opening angle of the craters by analyzing the textured surface. ${ }^{12}$ All approaches, however, provide only limited information on the wave propagation of light in a nanotextured thin film solar cell. The extracted parameters do not allow for a complete description of the nanotextured surface. Therefore, they cannot be directly correlated with the quantum efficiency and short circuit current of a solar cells prepared on a nanotextured surface.

We have developed an alternative approach that uses image segmentation techniques to analyze AFM images and extract the dimensions of individual craters or pyramids on the surface. The extracted dimensions were correlated with optical simulations of the wave propagation in solar cells with inverted pyramid (crater-like) textures. The combination of the surface analysis and the optical simulations can be used to derive design rules for optimization of the surface texture. The results of the approach are confirmed by experimental results of amorphous silicon solar cells prepared on nanotextured surfaces.

The textured zinc oxide films were prepared by radio frequency (rf) magnetron sputtering in an in-line sputtering system at $300^{\circ} \mathrm{C}$ substrate temperature. Films were subsequently etched in diluted hydrochloric $(\mathrm{HCl}, 0.5 \mathrm{w} / \mathrm{w} \%)$ and hydrofluoric (HF, $1 \mathrm{w} / \mathrm{w} \%$ ) acid solutions for 50 and $75 \mathrm{~s}$, respectively. SEM images of the zinc oxide films, textured by $\mathrm{HCl}$ and $\mathrm{HF}$, are shown in Fig. 2. A comparison of the SEM images reveals that the $\mathrm{HCl}$ etched film, as shown in Fig. 2(a), is characterized by fewer but larger craters. The HF etched film in Fig. 2(b) exhibits a larger number of smaller craters. The difference in the samples can be explained by the differences in the etching properties of $\mathrm{HF}$ and $\mathrm{HCl}$. HF molecules are smaller in size than almost all other acid molecules (including $\mathrm{HCl}$ ), this combined with 


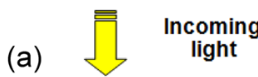

(b)

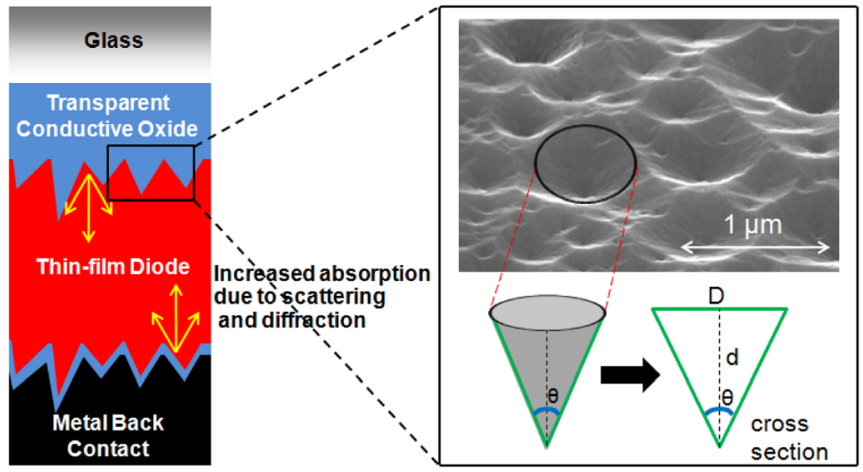

FIG. 1. (a) Cross sectional schematic of a silicon thin-film solar cell with randomly nanotextured contact layers. (b) SEM image of a textured zinc oxide film. The craters on the surface can be approximated by inverted cones. The dimensions of the cones can be described by the diameter (D), depth (d), and opening angle $(\theta)$ of the inverted cone, respectively.

the weak dissociation constant enables HF molecules to penetrate deeper and into more polycrystalline zinc oxide grain boundaries before dissociating and subsequently etching. ${ }^{13}$

In order to allow for a 3D analysis of the textured films, the surfaces were characterized by AFM. The individual craters on the zinc oxide surfaces were separated by an image segmentation algorithm applied to AFM data. The algorithm first finds all local minima (crater tips) and then subsequently determines the corresponding surrounding borders. The segmentation is illustrated in Figs. 2(c) and 2(d), where the borders of the individual craters are marked by black lines and the minima (tips) of the craters are marked by white points.

The crater-like surface of the zinc oxide films can be approximated by inverted cones. However, full surface coverage cannot be achieved using inverted cones with a circular (a)

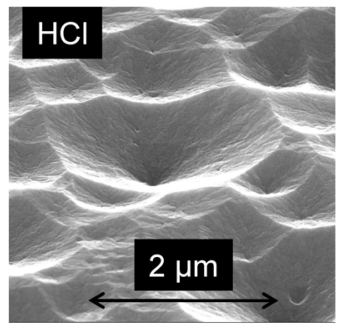

(b)

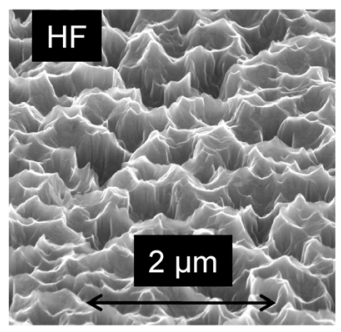

(c)



(d)



FIG. 2. SEM images of textured $\mathrm{ZnO}$ substrates etched with (a) $0.5 \mathrm{w} / \mathrm{w} \%$ $\mathrm{HCl}$ and (b) $1.0 \mathrm{w} / \mathrm{w} \% \mathrm{HF}$. Analysis of AFM images of the corresponding textured $\mathrm{ZnO}$ substrates etched with (c) $\mathrm{HCl}$ and (d) $\mathrm{HF}$. The local minima (crater tips) and the surrounding borders (black lines) were determined by an image segmentation algorithm. base. Therefore, to ensure full surface coverage, the inverted cones were mapped to inverted pyramids with a hexagonal base. As shown in Fig. 1(b), the dimensions of the pyramids can be described by the diameter $D$ and depth $d$. From the distributions of the diameters and depths of the inverted pyramids, it was found that the $\mathrm{HCl}$-etched sample exhibits a wide range of diameters. Eighty-five percent of all inverted pyramids on the surface have diameters in the range of $0.5-1.9 \mu \mathrm{m}$. On the other hand, the HF-etched sample has a much narrower diameter distribution. More than $95 \%$ of the inverted pyramids have diameters in the range of $0.2-0.8 \mu \mathrm{m}$. The depth distributions of the $\mathrm{HCl}$ etched sample and HF-etched sample were similar. Most of the inverted pyramids on both surfaces have depths in the range of $50-400 \mathrm{~nm}$. In the case of the $\mathrm{HCl}$-etched surface, there are deeper craters that go beyond $400 \mathrm{~nm}$ and $17 \%$ of the inverted pyramids have depths between $400 \mathrm{~nm}$ and $800 \mathrm{~nm}$.

In order to determine the optimal dimensions of the surface texture, optical simulations of amorphous silicon thin film silicon solar cells with integrated inverted pyramid texture were carried out. The 3D optical wave propagation in the solar cell was investigated by rigorously solving Maxwell's equations using finite difference time domain (FDTD) algorithm. FDTD is a numerically fast and robust technique, which is widely used in optical simulations for photovoltaic devices. ${ }^{14-19}$ The schematic cross section of an amorphous silicon solar cell on a nanotextured substrate is shown in Fig. 1(a). We assumed that the randomly textured surface can be approximated by a periodic surface structure. Haase et al. have shown that the short circuit current density of a solar cell on a quasi random substrate can be approximated as the area weighted superposition of the short circuit current density for solar cells with periodic surface texture. ${ }^{20}$

A unit cell of the periodically textured amorphous solar cell is shown in Fig. 3(a). The layer sequence of the amorphous silicon solar cell consists of an $800 \mathrm{~nm}$ thick aluminum-doped zinc oxide ( $\mathrm{ZnO}: \mathrm{Al})$ front contact. Afterwards, the inverter pyramids (craters) were etched in the zinc oxide film. The periodic surface texture can be described by pyramid diameter (D) and depth (d) as shown in Fig. 3(a). In this study, the
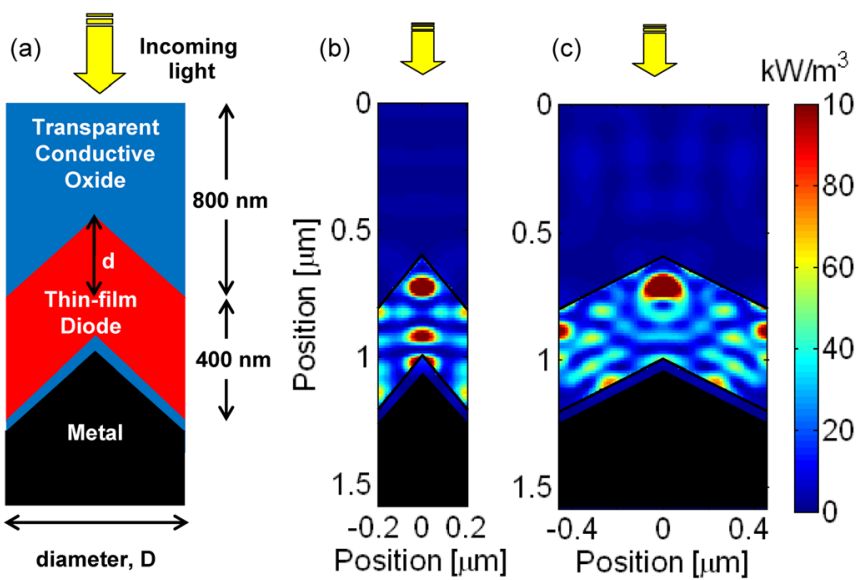

FIG. 3. (a) Unit cell of a periodically textured amorphous silicon solar cell. Also shown are the power loss maps of amorphous silicon solar cells under monochromatic illumination of wavelength $700 \mathrm{~nm}$. The dimension of periodic texture for the inverted pyramids were height, $\mathrm{d}=200 \mathrm{~nm}$ and periods of (b) $\mathrm{D}=400 \mathrm{~nm}$ and (c) $\mathrm{D}=900 \mathrm{~nm}$. 
pyramid period and height were varied from $50 \mathrm{~nm}$ to $3000 \mathrm{~nm}$ and $0 \mathrm{~nm}$ to $500 \mathrm{~nm}$, respectively. The front contact layer was followed by a hydrogenated amorphous silicon p-i-n diode $(a-\mathrm{Si}: \mathrm{H})$, which has a total thickness of $400 \mathrm{~nm}$ with p- and n-layer thicknesses of $10 \mathrm{~nm}$. The back reflector consists of an $80 \mathrm{~nm}$ thick $\mathrm{ZnO}: \mathrm{Al}$ layer and a perfect metal reflector. The complex optical constants of the individual layers were determined by transmission, reflection, and ellipsometry measurements of the individual layers. ${ }^{21}$ The simulations were executed by illuminating the unit cell under normal incidence for wavelengths ranging from $300 \mathrm{~nm}$ to $800 \mathrm{~nm}$. In the first step, the electric field distribution was calculated for the layer sequences. Then, the time average power loss was calculated. Figs. 3(b) and 3(c) show the cross sectional power loss maps of the investigated structure for textured solar cells with a crater depth of $200 \mathrm{~nm}$ and diameters of $400 \mathrm{~nm}$ and $900 \mathrm{~nm}$. The wavelength of the incident light was $700 \mathrm{~nm}$ for both the cases. Since this wavelength is close to the optical bandgap of amorphous silicon, the light is reflected and scattered by the front and back grating. For small periods $(\mathrm{p} \leq 150 \mathrm{~nm})$ of the inverted crater, the optical propagation can be described with effective medium theory. In such cases, the textured interface acts as matched layer in between the zinc oxide and the silicon layers. The power loss profile for a unit cell period of $400 \mathrm{~nm}$ [Fig. 3(b)] exhibits the regions of high absorption. For a larger period of $900 \mathrm{~nm}$ [Fig. 3(c)], the light is scattered in smaller angles and the average absorption in the unit cell drops.

The quantum efficiency was then calculated. The quantum efficiency is defined as the ratio of the power absorbed by the absorber (i-layer) of the solar cell to the total power incident on the solar cell. Finally, the short circuit current density was calculated for the spectral irradiance of Air Mass 1.5 (AM 1.5). Additional details on how to calculate time average power loss, quantum efficiency, and short circuit current density are given in Ref. 19. The simulated short circuit current density map of an amorphous thin film solar cell as a function of the inverted pyramid diameter and depth is shown in Fig. 4. The total thickness of the p-i-n diode was assumed to be $400 \mathrm{~nm}$. A solar cell without a surface texture (smooth $\mathrm{ZnO}$ substrate) exhibits a short circuit current density of $13.5 \mathrm{~mA} / \mathrm{cm}^{2}$. The highest short circuit current density $\left(18.5 \mathrm{~mA} / \mathrm{cm}^{2}\right)$ is observed for an inverted pyramid with diameter of $500 \mathrm{~nm}$ and depth of $500 \mathrm{~nm}$. This corresponds to more than $25 \%$ gain in the short circuit current density.

In Fig. 4(a), the short circuit current density map is overlaid with lines presenting different opening angles of the inverted pyramids. The short circuit current density increases substantially for opening angles smaller than $90^{\circ}$. The highest short circuit currents are achieved for opening angles between $30^{\circ}$ and $60^{\circ}$. The short circuit current density map, in Fig. 4(b), is overlaid with data points representing the crater dimensions (diameter and depth) of the zinc oxide films patterned by $\mathrm{HCl}$ and $\mathrm{HF}$. We assume that the diameter of the unit cell in the optical simulation is equal to the diameter of the crater extracted from the AFM images. The distributions of the craters for the two substrates can be fitted by lines. The opening angle of the HF textured is approximately equal to $70^{\circ}$. Small and big craters have almost identical opening angles. The situation is different for samples textured by $\mathrm{HCl}$. (a)


FIG. 4. Simulated short circuit current density maps for variations of inverted pyramid depths and periods for an amorphous silicon thin film solar cell. The maps are overlaid with (a) lines representing different opening angles of the inverted pyramid and (b) the extracted features dimensions from the investigated $\mathrm{HCl}$ and $\mathrm{HF}$ textured $\mathrm{ZnO}$ substrates.

For small craters, the opening angle approaches $140^{\circ}$. With increasing dimensions of the craters, the opening angle reduces to $120^{\circ}$. Therefore, the opening angle of the $\mathrm{HCl}$ substrate is comparable to the opening angles of craters etched into single crystal zinc oxide wafers. ${ }^{22}$ A comparison of the data points for the two substrates with the simulated short circuit current density shows that the area weighted superposition of short circuit current density is higher for the HF etched sample.

The observation from the simulation results is also confirmed by the experimental results. Thin film amorphous silicon solar cells were prepared on zinc oxide thin films etched in $0.5 \mathrm{w} / \mathrm{w} \% \mathrm{HCl}$, and $1.0 \mathrm{w} / \mathrm{w} \% \mathrm{HF}$. Etching times were adjusted such that approximately $150 \mathrm{~nm}$ of the originally $800 \mathrm{~nm}$ thick films were removed, as determined by surface profiler. The amorphous silicon $\mathrm{p}-\mathrm{i}-\mathrm{n}$ solar cells were prepared by plasma enhanced chemical vapor deposition (PECVD) at deposition temperatures below $200^{\circ} \mathrm{C}$. The intrinsic layer of the solar cell has a thickness of about $400 \mathrm{~nm}$. The $\mathrm{p}$ - and the n-layers have a thickness of about $10 \mathrm{~nm}$. The measured short circuit current densities of the solar cells are tabulated in Table I. The amorphous silicon solar cell prepared on the $\mathrm{HCl}$ textured substrate exhibited a short circuit current density of $14.1 \mathrm{~mA} / \mathrm{cm}^{2}$, while the HF textured substrate resulted in a short circuit current density of $15.4 \mathrm{~mA} / \mathrm{cm}^{2}$. The fill factor and open circuit voltage of the solar cells were approximately $70 \%$ and $900 \mathrm{mV}$, resulting in conversion efficiencies of almost $10 \%$. As a reference to these values, a solar cell prepared on a smooth substrate exhibits a short circuit current of $12.5 \mathrm{~mA} / \mathrm{cm}^{2}$. A summary of the measured and calculated short circuit current densities 
TABLE I. Experimentally measured short circuit current densities of amorphous silicon solar cells (i-layer thicknesses of $400 \mathrm{~nm}$ ) deposited on a smooth substrate and nanotextured substrates etched with $0.5 \mathrm{w} / \mathrm{w} \% \mathrm{HCl}$ and $1 \mathrm{w} / \mathrm{w} \% \mathrm{HF}$ acid solutions. As a reference to the simulation results, calculated short circuit current densities of two periodically textured solar cells are also tabulated.

\begin{tabular}{lccccc}
\hline \hline \multicolumn{2}{c}{ Experimentally measured short circuit current density } & & \multicolumn{2}{c}{ Calculated short circuit current density from simulations } \\
& $\mathrm{HCl}$ etched $\mathrm{ZnO}$ & $\mathrm{HF}$ etched ZnO & & $\mathrm{D}=900 \mathrm{~nm}, \mathrm{~d}=200 \mathrm{~nm}$ & $\mathrm{D}=400 \mathrm{~nm}, \mathrm{~d}=200 \mathrm{~nm}$ \\
Smooth substrate & $14.1 \mathrm{~mA} / \mathrm{cm}^{2}$ & $15.4 \mathrm{~mA} / \mathrm{cm}^{2}$ & & $15.5 \mathrm{~mA} / \mathrm{cm}^{2}$ & $17.2 \mathrm{~mA} / \mathrm{cm}^{2}$ \\
\hline \hline
\end{tabular}

is given in Table I. Further quantum efficiency curves and I-V data of the prepared solar cells are provided as supplementary information. ${ }^{23}$

Determining optimal light trapping structures is complex. The experimental description and characterization of randomly textured surfaces is in most cases based on the measurements of parameters like the haze in transmission or the angle dependent distribution of light scattering. However, these parameters provide only statistical information on the substrate and do not take into account the exact morphology of the surface. The approach presented here allows for the extraction of individual dimensions of craters or pyramids on a surface. Furthermore, the extracted parameters can be correlated with numerical simulation of solar cells with integrated surface textures.

The experimental results in Table I show that HF etched zinc oxide substrates exhibit higher short circuit currents than those of $\mathrm{HCl}$ etched substrates. In order to further increase the short circuit current, the opening angle of the surface texture has to be reduced further. Short wavelengths $(<500 \mathrm{~nm})$ are absorbed within the first few nanometers of the solar cell. Due to the large optical bandgap $(1.7 \mathrm{eV})$ of amorphous silicon, wavelengths ranging from $500 \mathrm{~nm}$ to $800 \mathrm{~nm}$ have to be efficiently diffracted and scattered. The optimal surface textures exhibit periods in the range of $250 \mathrm{~nm}-300 \mathrm{~nm}$. For microcrystalline silicon thin film solar cells, the optimal surface texture increases to approximately $1000 \mathrm{~nm} .{ }^{24}$ For the $\mathrm{HCl}$ substrate, an average diameter and depth of the inverted pyramid of $900 \mathrm{~nm}$ and $200 \mathrm{~nm}$ can be estimated. As shown in Table I, the calculated short circuit current density for the periodic structure with such dimension is $15.5 \mathrm{~mA} / \mathrm{cm}^{2}$. On the other hand, the average diameter and the depth of the HF etched substrate are estimated to be $400 \mathrm{~nm}$ and $200 \mathrm{~nm}$. For solar cells with such inverted pyramid dimension, the short circuit current increases up to $17.2 \mathrm{~mA} / \mathrm{cm}^{2}$. The optical simulations represent an upper limit of the short circuit current. The lower experimental short circuit current density can be attributed to non-ideal structure dimensions and to electrical losses in the solar cell. The next step is to extend the model so that the short circuit current density of solar cells can be directly calculated based on the measured surface profile.

In summary, an approach that allows the characterization and optimization of surface textures for thin film silicon solar cells was presented. Wet chemical etching of the contact layers can be used to control the scattering and diffraction of the incident light, such that the short circuit current and the conversion efficiency are maximized. We developed an approach that allows the extraction of the important sur- face parameters from atomic force microscope images. The extracted information of the randomly textured surfaces can be correlated with optical simulations of periodically textured thin film solar cells, so that optimized surface textures can be derived. The analysis was verified by experimental results. Amorphous silicon solar cells prepared on the optimized surface texture exhibited short circuit current densities of $15.4 \mathrm{~mA} / \mathrm{cm}^{2}$. This corresponds to almost $25 \%$ gain as compared to a solar cell prepared on a smooth substrate, yielding conversion efficiencies of almost $10 \%$.

${ }^{1}$ H. Sai, H. Fujiwara, M. Kondo, and Y. Kanamori, Appl. Phys. Lett. 93, 143501 (2008).

${ }^{2}$ J. Zhu, C.-M. Hsu, Z. Yu, S. Fan, and Y. Cui, Nano Lett. 10, 1979-1984 (2010).

${ }^{3}$ X. Sheng, J. Liu, I. Kozinsky, A. M. Agarwal, J. Michel, and L. C. Kimerling, Adv. Mater. 23, 843-847 (2011).

${ }^{4}$ M. Berginski, J. Hüpkes, M. Schulte, G. Schöpe, H. Stiebig, B. Rech, and M. Wuttig, J. Appl. Phys. 101, 074903 (2007).

${ }^{5}$ C. Battaglia, J. Escarré, K. Söderström, L. Erni, L. Ding, G. Bugnon, A. Billet, M. Boccard, L. Barraud, S. D. Wolf, F.-J. Haug, M. Despeisse, and C. Ballif, Nano Lett. 11, 661-665 (2011).

${ }^{6}$ A. Hongsingthong, T. Krajangsang, I. A. Yunaz, S. Miyajima, and M. Konagai, Appl. Phys. Express 3, 051102 (2010).

${ }^{7}$ V. E. Ferry, J. N. Munday, and H. A. Atwater, Adv. Mater. 22, 4794-4808 (2010).

${ }^{8}$ J. Krč, M. Zeman, O. Kluth, F. Smole, and M. Topič, Thin Solid Films 426, 296-304 (2003).

${ }^{9}$ D. Dominé, F.-J. Haug, C. Battaglia, and C. Ballif, J. Appl. Phys. 107, 044504 (2010).

${ }^{10}$ K. Bittkau, M. Schulte, M. Klein, T. Beckers, and R. Carius, Thin Solid Films 519, 6538-6543 (2011).

${ }^{11}$ R. H. Franken, R. L. Stolk, H. Li, C. H. M. van der Werf, J. K. Rath, and R. E. I. Schropp, J. Appl. Phys. 102, 014503 (2007).

${ }^{12}$ H. Stiebig, M. Schulte, C. Zahren, C. Haase, B. Rech, and P. Lechner, Proc. SPIE 6197, 232 (2006).

${ }^{13}$ J. I. Owen, J. Hüpkes, H. Zhu, E. Bunte, and S. E. Pust, Phys. Status Solidi A 208, 109-113 (2011).

${ }^{14}$ P. G. O'Brien, N. P. Kherani, S. Zukotynski, G. Ozin, E. Vekris, N. Tetreault, A. Chutinan, S. John, A. Mihi, and H. Míguez, Adv. Mater. 19, 4177-4182 (2007).

${ }^{15}$ D. Zhou and R. Biswas, J. Appl. Phys. 103, 093102 (2008).

${ }^{16}$ A. Lin and J. Phillips, Sol. Energy Mater. Sol. Cells 92, 1689-1696 (2008).

${ }^{17}$ V. E. Ferry, M. A. Verschuuren, H. Li, E. Verhagen, R. J. Walters, R. E. I. Schropp, H. A. Atwater, and A. Polman, Opt. Express 18(Suppl. 2), A237-245 (2010).

${ }^{18}$ S. B. Mallick, M. Agrawal, and P. Peumans, Opt. Express 18, 5691-5706 (2010).

${ }^{19}$ R. Dewan and D. Knipp, J. Appl. Phys. 106, 074901 (2009).

${ }^{20}$ C. Haase, U. Rau, and H. Stiebig, in 33rd IEEE Photovoltaic Specialists Conference (IEEE, 2008), p. 171.

${ }^{21}$ R. Dewan, S. Fischer, V. B. Meyer-Rochow, Y. Özdemir, S. Hamraz, and D. Knipp, Bioinspir. Biomim. 7, 016003 (2012).

${ }^{22}$ A. N. Mariano and R. E. Hanneman, J. Appl. Phys. 34, 384 (1963).

${ }^{23}$ See supplementary material at http://dx.doi.org/10.1063/1.4750242 for the experimental external quantum efficiency curves and $\mathrm{I}-\mathrm{V}$ data of $\mathrm{HCl}$ etched and HF etched amorphous silicon solar cells.

${ }^{24}$ R. Dewan, I. Vasilev, V. Jovanov, and D. Knipp, J. Appl. Phys. 110, 013101 (2011). 